Research Article

\title{
Simplified Calculation Method for Seismic Active Earth Pressure of Translational Retaining Wall considering Soil Arching Effect
}

\author{
Zheng-zhen Wang $\mathbb{D}$, Rang-cheng Kou $\mathbb{D}^{\mathbb{D}}$, Yong Zhou $\mathbb{D}$, and Tian-zhong Ma $\mathbb{i}$ \\ School of Civil Engineering, Key Laboratory of Disaster Mitigation in Civil Engineering of Gansu Province, \\ Lanzhou University of Technology, Lanzhou 730050, Gansu, China \\ Correspondence should be addressed to Yong Zhou; gsutzhouy@163.com
}

Received 29 September 2021; Revised 24 November 2021; Accepted 26 November 2021; Published 16 December 2021

Academic Editor: Denise-Penelope Kontoni

Copyright $\odot 2021$ Zheng-zhen Wang et al. This is an open access article distributed under the Creative Commons Attribution License, which permits unrestricted use, distribution, and reproduction in any medium, provided the original work is properly cited.

\begin{abstract}
At present, most seismic earth pressure theories have the limitations of complex derivation process and difficult solution. To solve these problems, considering the deflection of small principal stress caused by soil arching effect, the central arc soil arch was approximated to two inclined linear soil arches, which can greatly simplify the derivation process. Firstly, by improving the combination of differential thin-layer element method and pseudostatic method, the theoretical formulas of seismic active earth pressure intensity, resultant force size, and resultant force action point under translation mode (T mode) were derived and were verified by experimental results. Then, the influence of soil internal friction angle, wall-soil friction angle, and seismic coefficient on seismic active earth pressure theory was analyzed. The results show that the seismic active earth pressure is nonlinearly distributed, and the seismic horizontal coefficient has a greater influence than other influence factors. The theoretical results can provide reference for the seismic design of retaining wall.
\end{abstract}

\section{Introduction}

Seismic earth pressure calculation is an important part of retaining wall design. In recent years, with the frequent occurrence of earthquakes, seismic design has become particularly important. Therefore, it is necessary to derive the seismic earth pressure theory to provide reference for seismic design. The calculation methods of seismic earth pressure mainly include quasistatic method and quasidynamic method. Since the pseudodynamic method considers many parameters and the calculation is complex, no pseudostatic method is widely used. The quasistatic theory of Mononobe et al. [1] and Okabe [2] is the most authoritative. It regards the whole failure soil wedge as a rigid body and uses the external inertial force in the sliding body behind the wall to equivalent the seismic force. The dynamic problem is transformed into a static problem, and the obtained seismic soil pressure intensity is proportional to the wall height.
However, a large number of laboratory tests and field tests $[3,4]$ show that the seismic earth pressure distribution is nonlinear.

Lin et al. [5] derived the theoretical formula of earth pressure intensity, resultant force, and height of resultant force acting point of retaining wall under earthquake by using differential thin-layer element method. Sun [6] further promoted the application of differential thin-layer element method in the theory of seismic earth pressure calculation of retaining wall, which greatly increased the application scope of the deduced theory. However, neither of the above two papers considered the soil arching effect. In fact, because the back of the wall is not absolutely smooth, the wall-soil friction angle is not 0 , soil arching effect should exist. Subsequently, Hou et al. [7] considered the soil arching effect and assumed the soil arch shape was circular arc. Similarly, the differential thin-layer element method was used to derive the active earth pressure calculation formula of the soil 
behind the wall under earthquake action, but no displacement mode was considered. Zhang et al. [8] considered the soil arching effect and assumed that the shape of the soil arch was circular arc. Through the stress analysis of the soil behind the wall, the curve equation of the soil arch shape under seismic action was deduced. Then, the theoretical formulas of the active earth pressure distribution, the earth pressure resultant force, and the height of the resultant force point of the retaining wall under the translational mode were deduced, but the derivation process is often too complex. Therefore, some scholars began to seek a simplified method to calculate the earth pressure, Wang et al. [9] took the lead in the arc soil arch proposed by Ying et al. [10]; on the basis of the arc small principal stress axis approximate to a straight line to calculate the active earth pressure, compared with the arc soil arch derivation theory, the error is not big, but the calculation process is greatly simplified.

In summary, existing theories often ignore key factors or have complicated calculation processes. Therefore, in this paper, considering the soil arching effect and the translation mode, a new idea of simplifying the circular arch was proposed by using the differential thin-layer element method based on the central circular arch proposed by $\mathrm{Yu}$ et al. [11] and Zhang et al. [12]. The eccentric axis of the minor principal stress of the central circular arch was approximated to two inclined straight lines with an angle of $\theta$ with the vertical direction, which could simplify the calculation derivation and improve correctness. By approximating the microelement equilibrium equation of the postslip surface and the overall equilibrium equation of the soil arch, the theoretical formulas of the seismic active soil pressure intensity, the resultant force size, and the resultant force action point height under the translation mode ( $\mathrm{T}$ mode) were derived, and the rationality of the derived theory was verified by experiments. Subsequently, the influence of four main parameters (namely, internal friction angle, wallsoil friction angle, horizontal seismic coefficient, and vertical seismic coefficient) on the angle between the arch axis of small principal stress, the vertical direction of the retaining wall, seismic active earth pressure, and the height of the resultant force acting point were analyzed.

\section{Simplified Shape of Soil Arch and Calculation of Seismic Active Earth Pressure}

2.1. Simplified Shape of Soil Arch. Based on the assumption [12] that the soil arch is a circular arc arch (Figure 1), this paper approximates the deflection axis of small principal stress to two inclined straight lines (red lines in Figure 2) and makes the following assumptions: (1) the back of the retaining wall is upright and the filling surface behind the wall is horizontal; (2) the effect of ground loading is not considered; (3) the wall-soil friction angle $\delta$ is smaller than the internal friction angle $\varphi$; (4) M-O slip surface is used for slip surface in the limit state of soil, and the dip angle of slip surface is

$$
\begin{aligned}
& \beta=\arctan \left[\frac{s \cdot \sin \psi+\cos (\psi+\varphi+\delta)}{s \cdot \cos \psi-\sin (\psi+\varphi+\delta)}\right]-\psi, \\
& \psi=\arctan \frac{k_{h}}{1-k_{v}} \\
& s=\sqrt{\frac{\cos (\delta+\psi) \sin (\varphi+\delta)}{\sin (\varphi-\psi)}} .
\end{aligned}
$$

In the formula, $k_{h}$ is the horizontal seismic coefficient; $k_{v}$ is the vertical seismic coefficient; and $\psi$ is the seismic angle.

In Figure 1, the angle between the major principal stress of the differential sliding soil layer at the fracture surface and the horizontal plane and the angle between the major principal stress of the differential sliding soil layer at the back of the wall and the horizontal plane can be obtained by $\mathrm{Yu}$ et al. [11].

In Figures 1 and 2, $H$ is the height of the retaining wall; $\sigma_{1}$ is the principal stress; $\sigma_{3}$ is the small principal stress; $\mathrm{d} y$ is the thickness of circular arc soil arch; and $y$ is the distance from the upper part of the soil arch element to the top of the wall.

$$
\alpha_{w}=\alpha_{s}=\frac{\pi}{2}-\frac{\arcsin (\sin \delta / \sin \varphi)}{2}+\frac{\delta}{2}
$$

According to the geometric relationship, the angle between the arch axis of small principal stress and the vertical direction of retaining wall in Figure 3,

$$
\theta=\frac{\pi}{2}-\arctan \frac{1-\sin \alpha_{w}}{\cos \alpha_{w}}
$$

\subsection{Calculation of Seismic Active Earth Pressure}

2.2.1. Fundamental Equation. Two calculation models, the element force diagram at the sliding surface (Figure 4) and the microelement overall force analysis diagram (Figure 5), were used to solve the theoretical formula of seismic active soil pressure intensity by using the horizontal and vertical force analysis.

$A B$ is a rotation of dy and its value is $\sin \theta$ dy, which can be obtained from the geometry of Figure 4 .

$$
\left\{\begin{array}{l}
A D=\sin \theta \cdot \tan (\pi-\theta-\beta) \mathrm{dy} \\
B D=\frac{\sin \theta}{\cos (\pi-\theta-\beta)} \mathrm{dy} .
\end{array}\right.
$$

In Figure 5, the major principal stresses at each point on the whole soil arch are different, such as $\sigma_{\mathrm{F}}=\sigma_{\mathrm{E}}+\gamma(y) \mathrm{EF}$. Because (y)EF is small, the major principal stresses at each point in line $A B$ are replaced by $\sigma \mathrm{E}(\sigma 1)$ and so are other lines. The force on the line segment is equal to the stress of the vertical line segment multiplied by the length, such as (F) $A B=\sigma 1 \cdot(\mathrm{L}) A_{\mathrm{B}}$. 
The equilibrium equation can be got from the microelement diagram of the sliding surface in Figure 4, namely, the dotted line in Figure 3.

The static equilibrium in the horizontal direction of the virtual circle is as follows:

$$
\begin{aligned}
& \sigma_{1} \cos \theta \cdot L_{A D}+\sigma_{3} \sin \theta \cdot L_{A B}- \\
& \cdot \sigma_{s} \sin \beta \cdot L_{B D}+\tau_{s} \cos \beta \cdot L_{B D}-k_{h} d \mathrm{w}_{1}=0 .
\end{aligned}
$$

The static equilibrium in the vertical direction of the virtual circle is as follows:

$$
\begin{aligned}
& -\sigma_{1} \sin \theta \cdot L_{A D}+\sigma_{3} \cos \theta \cdot L_{A B}+ \\
& \quad \cdot \sigma_{s} \cos \beta \cdot L_{B D}+\tau_{s} \sin \beta \cdot L_{B D}-\left(1-k_{v}\right) \mathrm{dw}_{1}=0 .
\end{aligned}
$$

In this formula, $\sigma_{\mathrm{s}}$ is the normal stress of slip surface; $\mathrm{t}_{\mathrm{s}}$ is the tangential stress of slip surface; $d w_{1}$ is the self-weight of the sliding surface microelement soil in Figure 3.

$t_{\mathrm{s}}$ and $k_{\mathrm{a}}$ satisfy the following relation:

$$
\tau_{s}=\sigma_{s} \tan \varphi, k_{a}=\frac{\sigma_{3}}{\sigma_{1}}=\frac{1-\sin \varphi}{1+\sin \varphi} .
$$

From formulas (4) (7), formula (8) can be got

$$
\sigma_{s}=a \sigma_{1}
$$

In this formation,

$$
\begin{gathered}
a=\frac{\cos (\pi-\theta-\beta) k_{h}\left(k_{a} \cos \theta-\tan (\pi-\theta-\beta) \sin \theta\right.}{\left(1-k_{v}\right)(\tan \varphi \cdot \cos \beta-\sin \beta) t-n k_{h} q(\cos \beta+\tan \varphi \cdot \sin \beta)} \\
-\frac{\cos (\pi-\theta-\beta)\left(1-k_{v}\right)\left(\cos \theta \cdot \tan (\pi-\theta-\beta)+k_{a} \sin \theta\right)}{\left(1-k_{v}\right)(\tan \varphi \cdot \cos \beta-\sin \beta) t-n k_{h} q(\cos \beta+\tan \varphi \cdot \sin \beta)} .
\end{gathered}
$$

According to the geometric relationship in Figure 5,

$$
\left\{\begin{array}{l}
E I=d y, \\
E F=\frac{(H-y) \cot \beta}{2 \sin \theta}, \\
F D=\frac{(H-y) \cot \beta}{2 \sin \theta}, \\
B G=\frac{(H-y) \cot \beta}{2 \sin \theta}-\frac{\sin \theta \cos \beta}{\cos (\pi-\theta-\beta) \sin \theta} d y \\
G I=\frac{(H-y) \cot \beta}{2 \sin \theta} .
\end{array}\right.
$$

The equilibrium equation is listed from the detailed diagram of thin-layer differential element in Figure 5.

To establish a static equilibrium in the horizontal direction of the thin layer,

$$
\begin{aligned}
\sigma_{w} & \cdot L_{E I}-\tau_{s} \sin \beta \cdot L_{B D}+\tau_{s} \cos \beta \cdot L_{B D}+ \\
& \cdot\left(\sigma_{1}+d \sigma_{1}\right) \cos \theta \cdot L_{G I}-\left(\sigma_{1}+d \sigma_{1}\right) \cos \theta \\
& \cdot L_{B G}-k_{h} d w_{2}=0 .
\end{aligned}
$$

To establish a static equilibrium in the vertical direction of the thin layer,

$$
\begin{aligned}
\tau_{w} & \cdot L_{E I}+\sigma_{s} \cos \beta \cdot L_{B D}+\tau_{s} \sin \beta \cdot L_{B D}+\left(\sigma_{1}+d \sigma_{1}\right) \\
& \cdot \sin \theta\left(L_{G I}+L_{B G}\right)-\sigma_{1} \sin \theta\left(L_{E F}+L_{F D}\right)-\left(1-k_{v}\right) \mathrm{dw}_{2}=0 .
\end{aligned}
$$

In the formula, $\sigma_{w}$ is the normal stress at the back of the wall; $t_{w}$ is the tangential stress at the back of the wall; and $d w_{2}$ is the overall weight of the microelement soil in Figure 5, and

$$
\tau_{w}=\sigma_{w} \tan \delta, \mathrm{dw}=\gamma(H-y) \cot \beta d y .
$$

Ignore the second order trace, simplifying

$$
\frac{d \sigma_{1}}{d y}-\frac{b}{(H-y)} \sigma_{1}=c \gamma \text {. }
$$

In the formula,

$$
\begin{aligned}
b= & \frac{\sin \theta(\tan \delta \tan \varphi \cos \beta-\tan \delta \sin \beta-\tan \varphi \sin \beta-\cos \beta) a}{\cos (\pi-\theta-\beta) \cot \beta} \\
& +\frac{\sin \theta \cos \beta+\tan \delta \cos \theta \cos \beta}{\cos (\pi-\theta-\beta) \cot \beta} . \\
c= & \left(1-k_{\mathrm{h}} \tan \delta-k_{\mathrm{v}}\right) .
\end{aligned}
$$

$\sigma_{1}$ is the first-order differential equation about $y$, which can be solved by the separation of variables method.

$$
\sigma_{1}=(H-y)^{-b} \cdot\left(-c \gamma \frac{(H-y)^{b+1}}{b+1}+C\right) \text {. }
$$




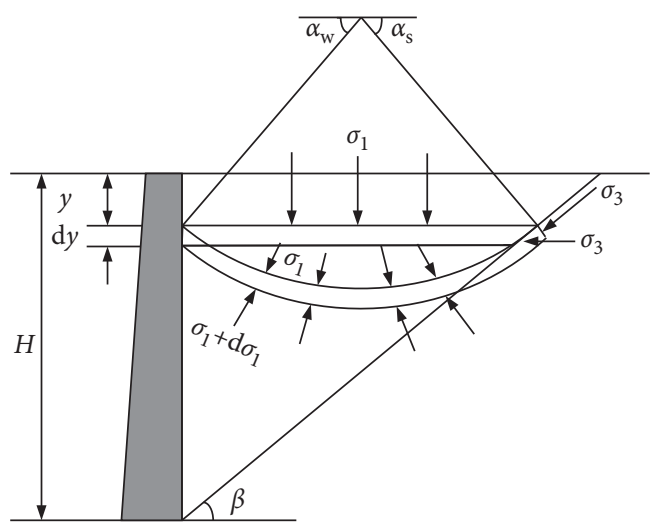

FIGURE 1: Arch shape of small principal stress.

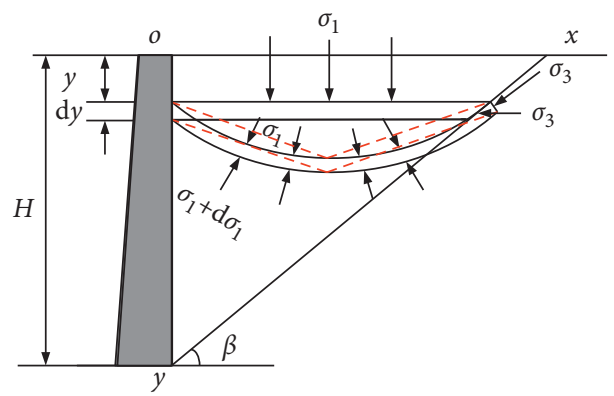

FiguRe 2: Simplification of small principal stress arch.

Formula: $C$ is a constant to be determined.

Substitute the boundary conditions $y=0, \sigma_{1}=0$ into (16):

$$
C=c \gamma \frac{H^{(b+1)}}{b+1}
$$

Substitute, (17) into (16):

$$
\sigma_{1}=c \gamma(H-y)^{(-b)}\left(\frac{H^{(b+1)}}{b+1}-\frac{(H-y)^{(b+1)}}{b+1}\right) .
$$

2.2.2. Seismic Active Earth Pressure Intensity Distribution. Formula (18) is replaced by formula (11) and the theoretical formula for calculating the seismic active earth pressure intensity under the translational mode of retaining wall is obtained.

$$
\sigma_{w}=d \gamma H\left(1-\frac{y}{H}\right)^{-b}-d \gamma(H-y)+\gamma k_{\mathrm{h}}(H-y) \cot \beta
$$

In the formula,

$$
d=\frac{a \sin \theta(\sin \beta-\tan \varphi \cos \beta)-\cos \theta \cos \beta}{\cos (\pi-\theta-\beta)(b+1)} c \text {. }
$$

2.2.3. Seismic Active Earth Pressure Resultant Force and Resultant Force Point Height. Seismic active earth pressure resultant force in horizontal direction can be obtained by integral formula (19) along the depth direction of retaining wall.

Total seismic active earth pressure resultant force:

$$
\begin{aligned}
P_{X} & =\int_{0}^{H} \sigma_{w} d y=\frac{1}{2} \gamma k_{\mathrm{h}} H^{2} \cot \beta+\left[\frac{1}{(1-b)}-\frac{1}{2}\right] d \gamma H^{2} . \\
P & =\frac{P_{X}}{\cos \delta} .
\end{aligned}
$$

The total bending moment of horizontal earth pressure on the bottom of the wall can be calculated by the following formula:

$$
M=\int_{0}^{H} \sigma_{w}(H-y) d y=\frac{1}{3} \gamma k_{\mathrm{h}} H^{3} \cot \beta+\left[\frac{1}{(2-b)}-\frac{1}{3}\right] d \gamma H^{3} .
$$

Equation (22) is divided by equation (21), and the distance between the position of the resultant force point and the end of the wall is

$$
h=\frac{M}{P_{X}}=\frac{1 / 3 k_{h} \cot \beta+[1 / 2-b-1 / 3] d \gamma}{1 / 2 k_{h} \cot \beta+[1 / 1-b-1 / 2] d \gamma} H .
$$

When $\delta=0$ and $\psi=0$, corresponding to $b=0$, it can be seen that under nonseismic action, the back of the wall is vertical and smooth, and the surface of the fill is horizontal. 


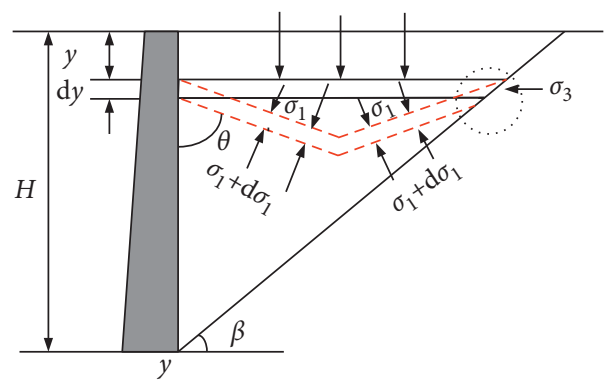

FIGURE 3: Simplified calculation model.

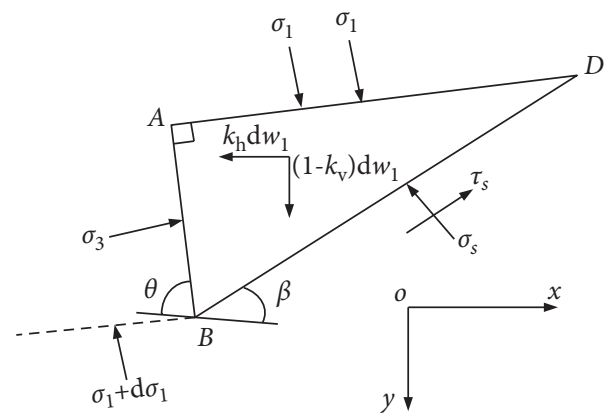

FIgURE 4: Unit stress diagram at slip surface.

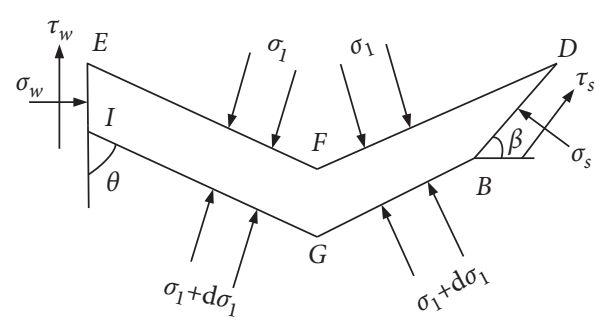

FIGURE 5: Force analysis diagram of microelement.

The action point of the resultant earth pressure is at $1 / 3$ of the wall height from the bottom of the wall, which is consistent with Rankine's active earth pressure theory.

\section{Experimental Verification}

3.1. Verification of Seismic Active Earth Pressure Intensity. In order to test the applicability of the method described in this paper, the rationality of the theoretical derivation in this paper is verified by the theoretical and experimental results of others. Table 1 shows the maximum value $\sigma_{\text {wmax }}\left(\mathrm{kN} \cdot \mathrm{m}^{-2}\right)$ of seismic active earth pressure in $\mathrm{T}$ mode calculated by formula (19) and the theoretical solutions of Zhang et al. [8] and Zhu et al. [13]. The measured parameters are $\varphi=40.6$, $\delta=15.9, \gamma=27.1 \mathrm{kN} / \mathrm{m}^{3}$, and $k_{\mathrm{v}}=0$.

It can be seen from Table 1 that when $k_{\mathrm{h}}=0$ and $k_{\mathrm{h}}=0.22$, the calculation results of this paper and the results of Zhang et al. [8] are in good agreement with the experimental results; when $k_{\mathrm{h}}=0.3, k_{\mathrm{h}}=0.327$, the calculated results and Zhang et al.'s [8] results are quite different from the experimental results.

The experimental data show that when the seismic active earth pressure intensity is large, the experimental results and theoretical deviation are large. This is because the displacement mode is assumed to be translation mode. When the horizontal seismic coefficient is large, the retaining wall does not cause translation. Therefore, the calculated seismic active earth pressure intensity is greatly different from the experimental value and increases with the increase of seismic coefficient. However, when $k_{\mathrm{h}}$ is small $\left(k_{\mathrm{h}}<0.22\right)$, the deviation is small, and the method in this paper is in good agreement with the experimental value. Therefore, the theory deduced in this paper is reasonable.

3.2. The Height Verification of Resultant Force Action Point. Test data of Sherif et al. [4] and theories of Zhang et al. [12] and Liu et al. [14] are used to verify the rationality of the theoretical derivation. 
TABLE 1: Theoretical analytical solution and measured results.

\begin{tabular}{lcccc}
\hline$k_{\mathrm{h}}$ & $H / \mathrm{m}$ & Present results $\left(\mathrm{kN} \cdot \mathrm{m}^{-2}\right)$ & ${\text { Experimental result }\left(\mathrm{kN} \cdot \mathrm{m}^{-2}\right)}^{\text {Zhang }}$ & Qichang $\left(\mathrm{kN} \cdot \mathrm{m}^{-2}\right)$ \\
\hline 0 & 0.62 & 1.58 & 1.36 & 1.67 \\
0.22 & 0.54 & 2.41 & - & 1.82 \\
0.3 & 0.54 & 5.58 & 2.03 & 5.16 \\
0.327 & 0.5 & 9.40 & 3.89 & 10.24 \\
\hline
\end{tabular}

Figure 6 is the comparison of the height of earth pressure resultant force calculated by this method with other methods and Sherif et al.'s [4] test data. It can be seen that after simplifying the shape of soil arch, compared with Liu et al.'s [14] method, $k_{\mathrm{h}}<0.07$, the calculated resultant force point is reduced, compared with Zhang et al.'s [12] method; when $k_{\mathrm{h}}>0.07$, the calculated resultant force point is increased. The results calculated in this paper are closer to the experimental results than those calculated by Liu et al. [14], no method was proposed by Zhang et al. [12], which is close to the experimental results. This is because Liu et al. [14] adopted Rankine slip surface, and the assumption is too ideal. In order to simplify the calculation, the method proposed in this paper also simplifies the shape of soil arch, so there will be some errors. However, in general, the height of resultant force action point calculated by this method is relatively close to that calculated by experimental data and other two methods.

\section{Parametric Analysis}

4.1. Angle between Arch Axis of Small Principal Stress and Vertical Direction of Retaining Wall. Keeping the wall-soil friction angle $(\delta=10)$, vertical seismic coefficient $\left(k_{v}=0.1\right)$, retaining wall height $(H=4 \mathrm{~m})$, and soil weight $\left(\gamma=18 \mathrm{kN} / \mathrm{m}^{3}\right)$ unchanged, the internal friction angles $\varphi$ of soil were taken as $30^{\circ}, 35^{\circ}, 40^{\circ}$, and $45^{\circ}$, respectively, and the horizontal seismic coefficient was taken as the abscissa to analyze the influence of different internal friction angles and horizontal seismic coefficients on the angle between the arch axis of small principal stress and the vertical direction of retaining wall (Figure 7).

The angle $\theta$ between the axis of the small principal stress arch and the vertical direction of the retaining wall increases with $\varphi$. The larger the $k_{\mathrm{h}}$ is, the larger the increase rate is. With the increase of $k_{\mathrm{h}}, \theta$ decreases. The smaller the $\varphi$ is, the greater the decrease rate is. It can be clearly seen that $\varphi$ has a small influence on $\theta$, while $k_{\mathrm{h}}$ has a great effect.

Keeping the internal friction angle $\left(\varphi=40^{\circ}\right)$, horizontal seismic coefficient $\left(k_{\mathrm{h}}=0.4\right)$, retaining wall height $(H=4 \mathrm{~m})$, and soil weight $(\gamma=18 \mathrm{kN} / \mathrm{m} 3)$ unchanged, the wall-soil friction angle $\delta$ of soil was taken as $0^{\circ}, 10^{\circ}, 20^{\circ}$, and $30^{\circ}$, respectively, and the vertical seismic coefficient was taken as the abscissa to analyze the influence of different wall-soil friction angles and vertical seismic coefficients on the angle between the arch axis of small principal stress and the vertical direction of retaining wall (Figure 8).

The angle $\theta$ between the axis of the small principal stress arch and the vertical direction of the retaining wall decreases with the increase of $\delta$, and $k_{v}$ has little effect on the decrease. As $k_{v}$ increases, $\delta$ has little effect on the decrease. It can be seen that $\delta$ has a great influence on $\theta$, that is, on soil arching effect; $k_{v}$ has little effect on $\theta$, that is, it has little effect on soil arching effect. This is consistent with the conclusion drawn by many experts and scholars (soil arching effect is related to the wall-soil friction angle $\delta$ ).

4.2. Seismic Active Earth Pressure Distribution. Keeping the retaining wall height $(H=4 \mathrm{~m})$ and soil mass $(\gamma=18 \mathrm{kN} /$ $\mathrm{m}^{3}$ ) unchanged, the relationship between active earth pressure distribution calculated by formula (17) and horizontal seismic coefficient $k_{\mathrm{h}}$, vertical seismic coefficient $k_{\mathrm{v}}$, internal friction angle $\varphi$, and wall-soil friction angle $\delta$ is analyzed.

The seismic active earth pressure decreases with the increase of $\varphi$, and the decrease is significant. In the middle and lower parts of the retaining wall, the decrease is the most significant. With the increase of $\delta$, the increase is not obvious. Moreover, with the decrease of $\varphi$ and the increase of $\delta$, the graphic centroid composed of the $\sigma_{\mathrm{w}} / \gamma H$ curve and the ordinate axis gradually increases.

The seismic active earth pressure shows an increasing trend with the increase of $k_{\mathrm{h}}$, and the increase degree is relatively significant. At the top of the wall, the increase degree is the most significant. With the increase of $k_{\mathrm{v}}$ which shows a decreasing trend, the degree of decrease is not obvious.

From Figures 9-12, it can be clearly seen that the seismic active earth pressure increases first and then decreases, and the maximum value appears in the middle and lower parts of the retaining wall. At the bottom of the wall, no matter how the horizontal seismic coefficient changes, the seismic active earth pressure is always 0 . Moreover, due to the influence of earthquake, at the beginning of the wall height, the seismic active earth pressure is not 0 , and the horizontal seismic coefficient has the most significant influence on the seismic active earth pressure. It can also be seen that $\varphi$ and $k_{\mathrm{h}}$ have great influence on the distribution of seismic active earth pressure, and $\delta$ and $k_{\mathrm{v}}$ have little influence on the distribution of seismic active earth pressure.

4.3. Height of Resultant Point. Keeping the height of retaining wall $(H=4 \mathrm{~m})$ and soil mass $\left(\gamma=18 \mathrm{kN} / \mathrm{m}^{3}\right)$ unchanged, the relationship between the height of resultant force point and horizontal seismic coefficient $k_{\mathrm{h}}$ and vertical seismic coefficient $k_{\mathrm{v}}$ is analyzed.

The height of the resultant force point increases with the increase of $\delta$. As $\varphi$ increases, the larger the $\delta$ is, the larger the increase is. It increases with the increase of $k_{\mathrm{v}}$, and the greater the $k_{\mathrm{h}}$, the greater the increase. As $k_{\mathrm{h}}$ increases, the larger $k_{\mathrm{v}}$, the greater the increase. 


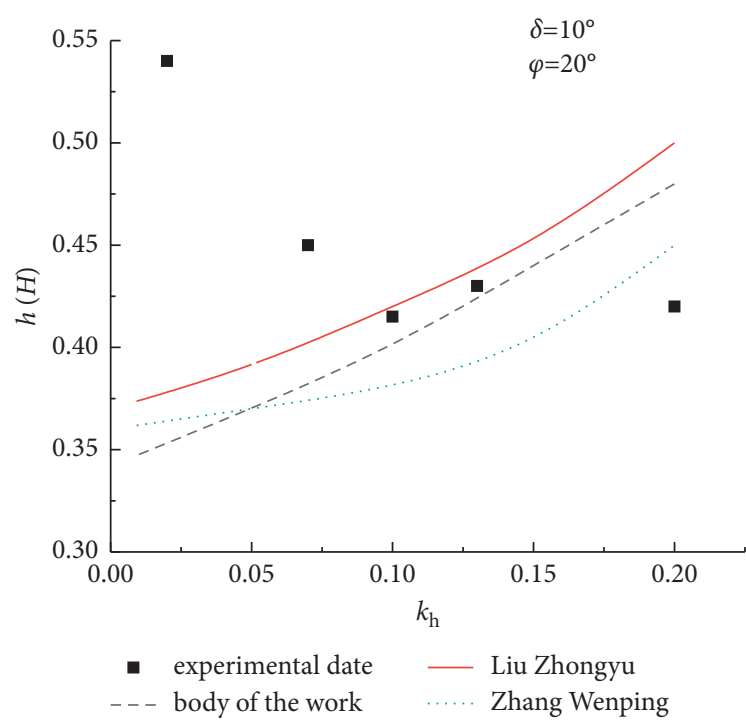

Figure 6: Comparison of experimental data and height of joint action point of different methods.

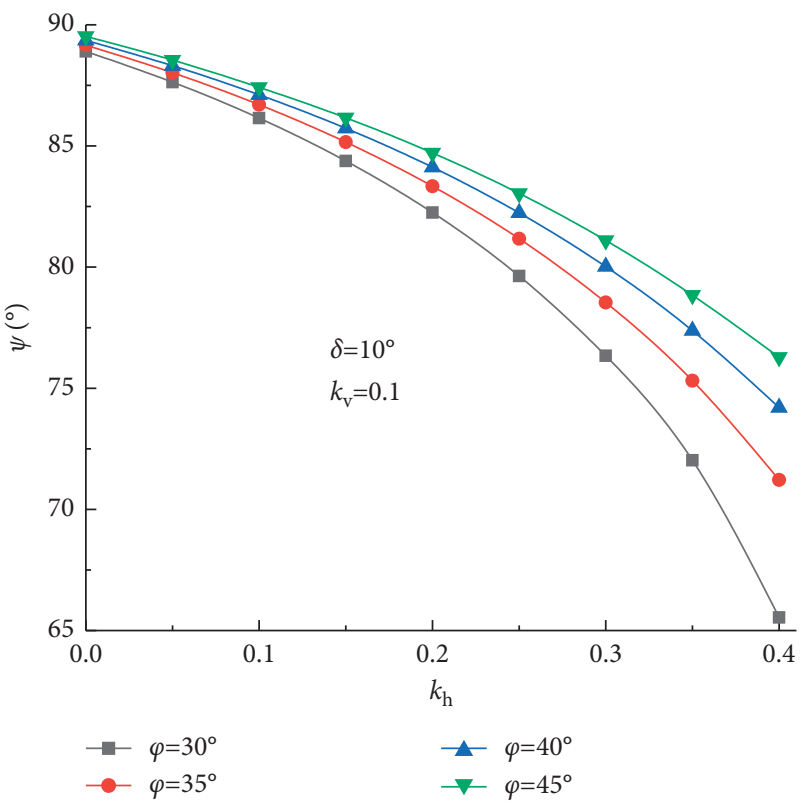

FIgURE 7: $\theta$ curve of variation with $(\mathrm{k})_{\mathrm{h}}$ and $\varphi$.

From Figures 13 and 14, it can be seen that the height of the resultant force action point is always higher than that of Rankine earth pressure resultant force action point $H / 3$, and with the increase of $\delta$ and $\varphi$, the range of resultant force action point is large. When $\delta$ is small and $\varphi$ changes, the resultant force action point is almost the same. With the increase of $\delta$, the range of resultant force action point is large; with the increase of $k_{\mathrm{h}}$ and $k_{\mathrm{v}}$, the range is large. When $k_{\mathrm{h}}$ is small and $k_{\mathrm{v}}$ changes, the resultant force point is almost the same. With the increase of $k_{\mathrm{h}}$, the range is large. Therefore, we can see that $\delta$ and $k_{\mathrm{h}}$ are the main factors affecting the height of the resultant force point, and $\varphi$ and $k_{\mathrm{v}}$ have little effect on the height of the resultant force point. 


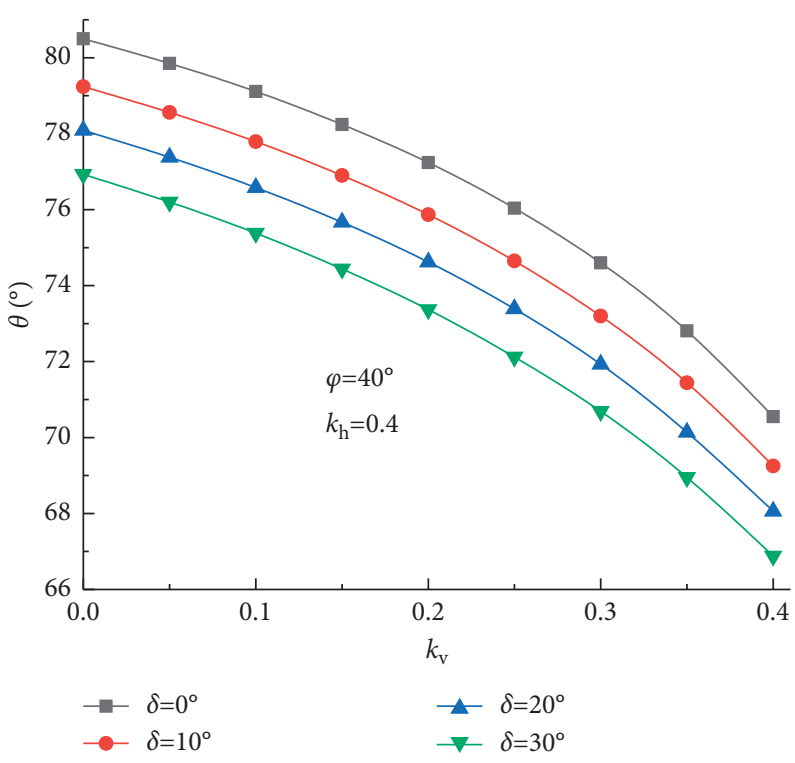

Figure 8: $\theta$ curve of variation with $(\mathrm{k}) \mathrm{v}$ and $\delta$.

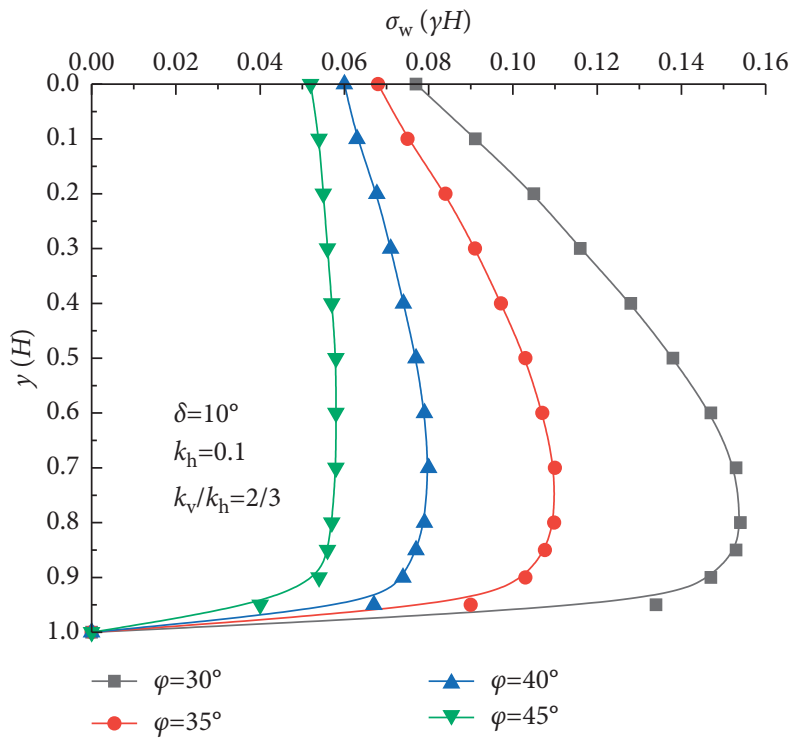

FIGURE 9: Influence of $\varphi$ on seismic active earth pressure distribution. 


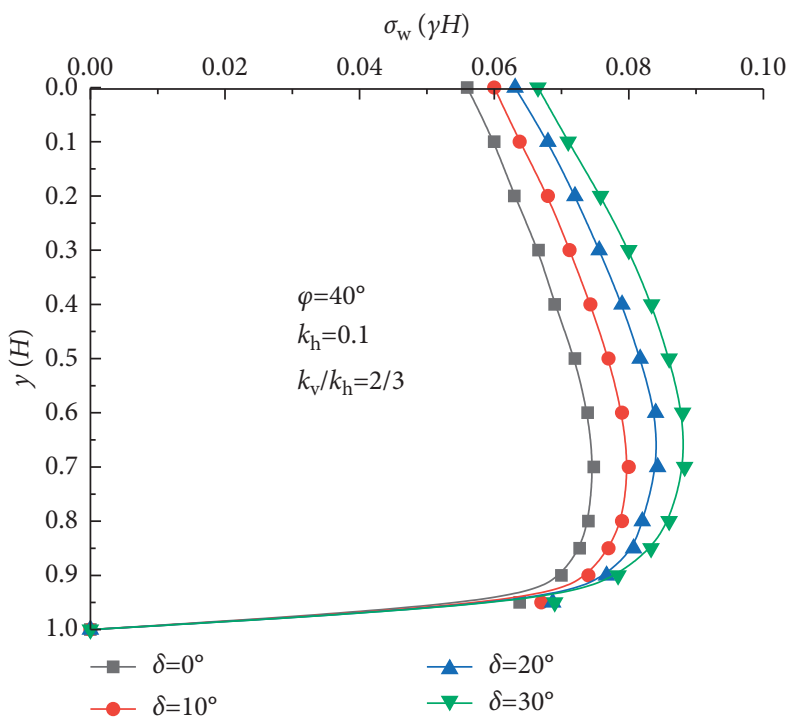

FIGURE 10: Influence of $\delta$ on seismic active earth pressure distribution.

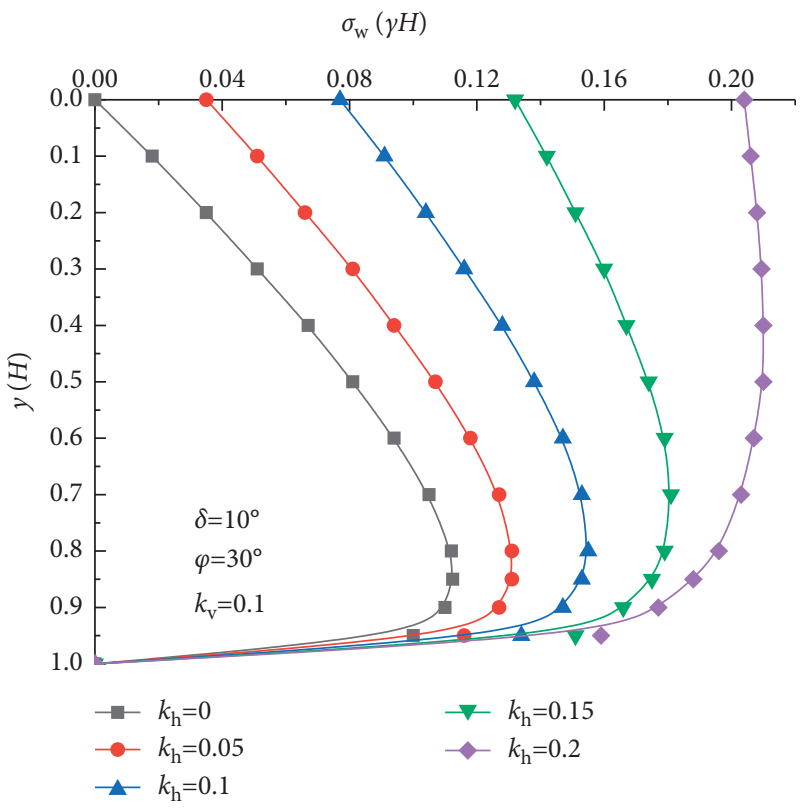

FigURE 11: Influence of $(\mathrm{k})_{\mathrm{h}}$ on seismic active earth pressure distribution. 


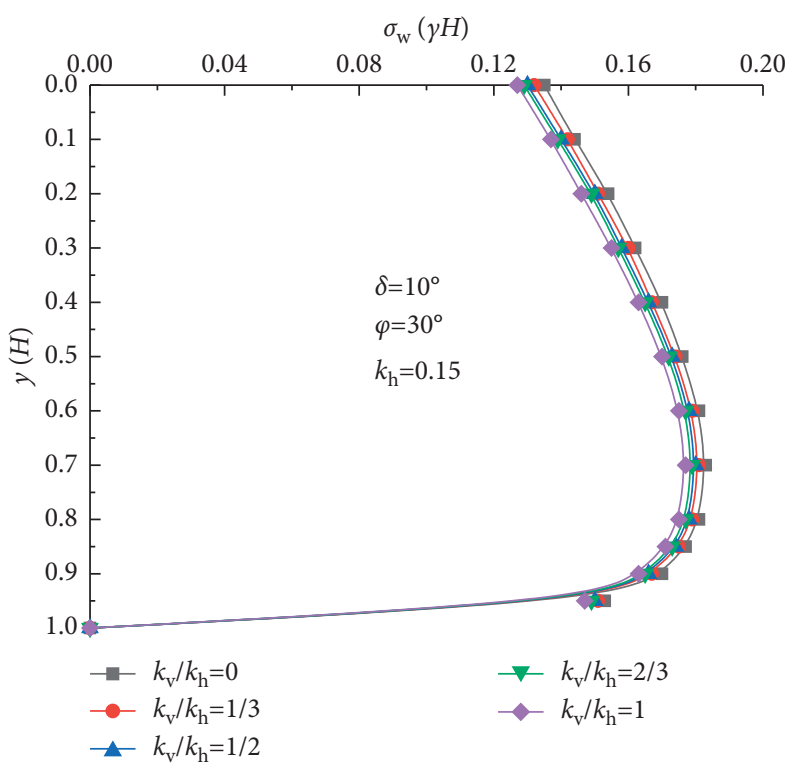

FIGURE 12: Influence of $(\mathrm{k})_{\mathrm{v}}$ on seismic active earth pressure distribution.

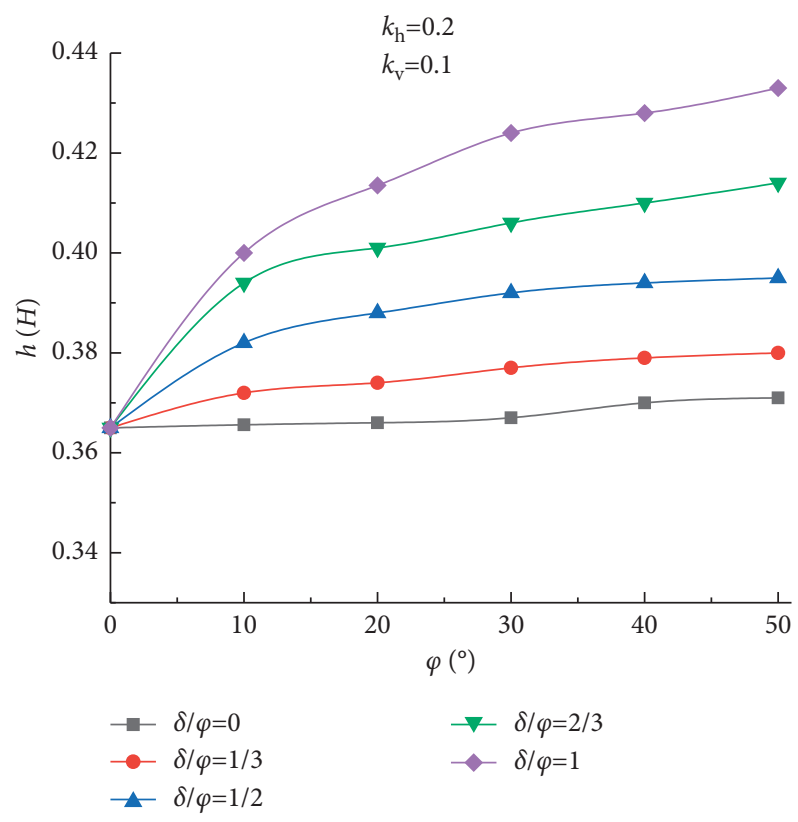

FIgURE 13: The variation curve of the height of the resultant force acting point with $\delta$ and $\varphi$. 


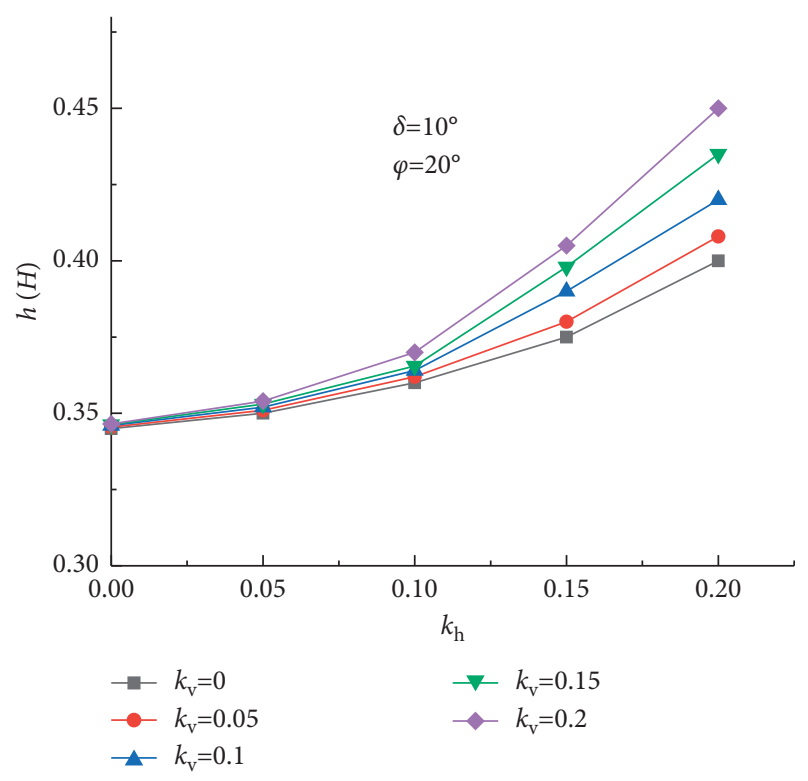

FIGURE 14: The variation curve of the height of the resultant force acting point with $(k) h$ and $(k) v$.

\section{Conclusion}

(1) The seismic active earth pressure theory derived in this paper is simpler than the previous theory, which can be used in practical engineering and provide theoretical guidance for seismic design of retaining walls.

(2) The height of resultant force action point is in the range of $1 / 3 H$ to $1 / 2 H$ and is always greater than the result of Rankine earth pressure.

(3) The horizontal seismic coefficient and the wall-soil friction angle have a great influence on the soil arch effect. But vertical seismic coefficient and internal friction angle have little effect on soil arching effect.

\section{Data Availability}

The data used to support the findings of this study are included within the article.

\section{Conflicts of Interest}

The authors declare that they have no conflicts of interest.

\section{Acknowledgments}

This work was supported by the National Natural Science Foundation of China (Grant no. 52068048) and the Natural Science Foundation of Gansu (Grant no. 20JR10RA163).

\section{References}

[1] N. Mononobe and M. Matsuo, "On the determination of earth pressures during earthquakes," Proceedings World Engineering Congress, vol. 9, no. 5, pp. 179-187, 1929.

[2] S. Okabe, "General theory of earth pressure," Journal of the Japanese Society of Civil Engineers, vol. 12, no. 1, pp. 123-134, 1926.
[3] K. Terzaghi, Theoretical Soil mechanics, Wiley, New York, NY, USA, 1943.

[4] M. A. Sherif, I. Ishibashi, and C. D. Lee, "Earth pressures against rigid retaining walls," Journal of the Geotechnical Engineering Division, vol. 108, no. 5, pp. 679-695, 1982.

[5] Y. L. Lin, G. L. Yang, and L. H. Zhao, "Study on active earth pressure of viscous soil behind retaining wall under earthquake," Rock and Soil Mechanics, vol. 32, no. 8, pp. 2479-2486, 2011.

[6] Y. Sun, "Unified solution of active earth pressure and its distribution on retaining wall under seismic conditions," Rock and Soil Mechanics, vol. 33, no. 1, pp. 256-261, 2012.

[7] J. Hou, T. Xia, W. Chen, and X. Kong, "Static study of seismic active earth pressure on retaining wall considering soil arching effect," Chinese Journal of Rock Mechanics and Engineering, vol. 32, no. S1, pp. 2825-2832, 2013.

[8] Q. C. Zhang, X. Lu, and D. Li, "Seismic active earth pressure analysis of moving retaining wall considering soil arching effect," Journal of Tianjin University, vol. 48, no. 12, pp. 1063-1070, 2015.

[9] M. Wang and J. P. Li, "Calculation method of active earth pressure of rigid retaining wall considering soil arching effect," Chinese Journal of Geotechnical Engineering, vol. 35, no. 5, pp. 865-870, 2013.

[10] H. W. Ying, B. Jiang, and K. H. Xie, "Active earth pressure distribution of retaining wall considering soil arching effect," Chinese Journal of Geotechnical Engineering, vol. 29, no. 5, pp. 717-722, 2007.

[11] J. Yu, Y. Zhou, Y. Cai, and B. Tu, "Active earth pressure behind rigid retaining wall based on soil arch effect," Chinese Journal of Geotechnical Engineering, vol. 35, no. 12, pp. 2307-2310, 2013.

[12] W. Zhang, Y. Zhou, J. Yu, B. Tu, and Y. Cai, "A seismic earth pressure algorithm for translation retaining wall considering principal stress deflection," Journal of Underground Space and Engineering, vol. 15, no. 6, pp. 1772-1779, 2019.

[13] T. H. Zhu, S. Z. Zheng, and Y. Z. Lan, "Model test for simulating earth pressure of gravity retaining wall under seismic load," Building Science Research of Sichuan Province, vol. 1, no. 7, pp. 35-37, 1983.

[14] Z. Y. Liu, H. P. Yang, and S. D. He, "Nonlinear distribution of seismic active earth pressure of rigid retaining wall," Journal of Zhengzhou University, vol. 39, no. 2, pp. 36-38, 2004. 